\title{
TRADISI LISAN MAMONGOTI BAGAS (MEMASUKI RUMAH BARU) DALAM MASYARAKAT BATAK TOBA
}

\author{
(Oral Tradition Mamongoti Bagas (Entering the New House) in the Batak Toba \\ Community)
}

\author{
Heleri Mariani Sinabutar ${ }^{\mathrm{a}}$, HamzonSitumorang $^{\mathrm{b}}$, dan Eddy Setia ${ }^{\mathrm{c}}$ \\ Fakultas Ilmu Budaya, Universitas Sumatera Utara \\ Pos-el: helerisinabutar@gmail.com
}

tanggal naskah masuk 23 Januari 2019

tanggal akhir penyuntingan 16 Juni 2019

\begin{abstract}
This research discuss about the oral tradition mamongoti bagas (enter new house) in Batak Toba society. The theory used is theory text, kotex and the context and local wisdom.The Method used is descriptive qualitative. The data is series of the event enter new house in Batak Toba society.The results show that text in the event enter a new house in Batak Toba society has a meaning to form new social relationships. Kotex contains elements prosemik where there is a pause of speakers, sotah we know position of person in the event enter a new house in Batak Toba society. The context is about context situation, social and place.The event enter new house contains three local wisdom, namely thanksgiving, harmony and peace, and caring environment. It can be concluded that oral tradition enter a new house in batak toba society contains local wisdom tah must be protected and preserved.
\end{abstract}

Keywords: mamongoti bagas, Batak Toba Society, oral tradition, local wisdom

\begin{abstract}
Abstrak
Penelitian ini membahas tentang tradisi lisan mamongoti bagas (memasuki rumah baru) dalam masyarakat Batak Toba. Teori yang digunakan adalah teori Teks, Koteks dan Konteks dan Kearifan Lokal. Metode yang digunakan adalah metode deskriptif kualitatif. Datanya adalah serangkaian acara memasuki rumah baru masyarakat Batak Toba. Hasilnya menunjukkan bahwa teks dalam acara memasuki rumah baru dalam masyarakat Batak Toba memiliki makna pembentukan hubungan sosial yang baru. Koteks mengandung unsur prosemik dimana ada jeda diantara penutur, sehingga kita tahu apa posisi seseorang dalam acara memasuki rumah baru dalam masyarakat Batak Toba. Konteks yang terdapat adalah konteks situasi, sosial dan tempat. Acara memasuki rumah baru mengandung tiga kearifan lokal, yaitu ucapan syukur, kerukunan dan kedamaian, dan peduli lingkungan. Dari pembahasan tersebut, dapat disimpulkan bahwa tradisi memasuki rumah baru dalam masyarakat Batak Toba mengandung kearifan lokal yang harus dijaga dan dilestarikan sebagai tradisi lisan masyarakat Batak Toba.
\end{abstract}

Kata-kata kunci: mamongoti bagas, masyarakat Batak Toba, tradisi lisan, kearifan lokal

\section{PENDAHULUAN}

Setiap suku bangsa di Nusantara memilliki beragam bentuk tradisi yang khas. Tradisi lokal ini sering disebut dengan kebudayaan lokal (local culture), yang hidup di tengah-tengah masyarakat. Meskipun masyarakat pendukungnya mengalami perubahan, tetapi tradisi tetap 
ada. Salah satu bentuk tradisi yang masih berkembang sampai sekarang adalah tradisi lisan. Awal mula tradisi lisan berkembang di Indonesia adalah adanya bentuk interaksi secara lisan dalam suatu masyarakat yang memiliki adat istiadat atau tradisi, sehingga pada saat itu tradisi kelisanan lebih mendominasi daripada tradisi keberaksaraan.

Tradisi lisan (oral tradition) dapat diartikan sebagai kebiasaan atau adat yang berkembang dalam suatu komunitas masyarakat yang direkam dan diwariskan dari generasi ke generasi melalui bahasa lisan. Tradisi lisan menjadi bagian dari warisan budaya bangsa yang ditetapkan dalam konvensi UNESCO tertanggal 17 September 2003. Pudentia (2007: 27) mendefenisikan tradisi lisan sebagai wacana yang diucapkan atau disampaikan secara turun-temurun meliputi yang lisan dan yang beraksara, yang kesemuanya disampaikan secara lisan.Tradisi lisan, dengan tradisi dan adat istiadat masyarakat, merupakan aset budaya yang penting dan berharga yang layak untuk dikaji dan dilestarikan karena tradisi lisan merupakan kekuatan kultural dalam pembentukan identitas dan karakter bangsa. Hal ini diperkuat oleh Sibarani (2012: 15) yang mengatakan bahwa tradisi lisan dapat menjadi kekuatan kultural dan salah satu sumber utama yang penting dalam pembentukan identitas dan membangun peradaban.

Tradisi memasuki rumah baru (mamongoti bagas) pada hakikatnya merupakan warisan leluhur bangsa Indonesia yang terdapat didalam berbagai daerah dan etnik di Indonesia dengan berbagai variasi, istilah dan penerapannya. Meskipun istilah dan penerapannya bervariasi, pada hakikatnya semua yang menyangkut tradisi memasuki rumah baru berkaitan dengan upacara adat.

Bagi Orang Batak, rumah merupakan cita-cita yang paling diprioritaskan dalam hidupnya. Rumah merupakan sesuatu yang sangat didambakan, agar menjadi tempat bernaung, berlindung dikala hujan dan terik matahari, dikala malam agar tidak kedinginan dan sebagai tempat memulai segala aktivitas dan keberangkatan menuju tempat kerja. Rumah juga menjadi tempat mengumpulkan segala rejeki yang didapat dari pekerjaannya untuk dinikmati (dihalashon) oleh seluruh anggota keluarga. Rumah merupakan tempat yang dirindukan anggota keluarga yang ingin segera kembali dari tempat kerja maupun perjalanan. Itulah sebabnya, apabila seorang keluarga Batak sudah bisa membangun rumah untuk tempat keluarga bernaung, itu menjadi sebuah kebahagiaan dan rasa syukur sehingga sebelum rumah 
baru ditempati, keluarga tersebut akan membuat acara syukuran adat memasuki rumah baru.

Dewasa ini, tidak lagi semua masyarakat Batak Toba membuat acara memasuki rumah baru (mamongoti bagas), khususnya masyarakat Batak Toba yang tinggal diperkotaan. Banyak masyarakat Batak Toba tidak lagi membuat acara adat ketika memasuki rumah baru, mereka kemungkinan hanya membuat acara syukuran kecil-kecilan (partangiangan) berdoa bersama tanpa melaksanakan upacara adat batak sesuai dengan tatanan adat memasuki rumah baru dalam masyarakat Batak Toba. Meskipun demikian, pada umumnya, masyarakat Batak Toba melaksanakan tradisi mamongoti bagas (memasuki rumah) sebagai ucapan syukur kepada Tuhan karena sudah bisa membangun rumah yang bagus dilihat, serta meminta doa agar mereka tetap dalam keadaan sehat menempati rumah yang sudah dibangun tersebut. Maka, sebagai sebuah tradisi dan budaya, sudah sepatutnyalah acara mamongoti bagas (memasuki rumah) dipertahankan dan dilestarikan karena tradisi tersebut mencerminkan dan merupakan jati diri masyarakat Batak Toba dimanapun masyarakat Batak Toba berada.

Dalam acara memasuki rumah baru, yang empunya rumah (suhut) akan mengundang dongan tubu (teman semarga), dongan sahuta (teman sekampung), boru (pihak perempuan yang semarga dengan yang empunya rumah/suhut), hula hula (keluarga yang semarga dengan pihak istri), tulang (paman) dan pariban (perempuan yang semarga dengan boru istri yang empunya rumah). Biasanya acara dimulai pukul 09.00 pagi yaitu dimulai dari acara kebaktian, dibuka oleh Bapak Pendeta, dan biasanya Bapak Pendeta akan memegang kunci rumah dan akan membukakan pintu rumah. Setelah acara kebaktian, acara adat akan dimulai pada pukul 10.00 (parnakkok ni mata ni ari) matahari mulai menanjak agar kesehatan dan kesejahteraan (panggabean dohot parhorasan) juga meningkat di kemudian hari. Acara adat akan dimulai dengan pihak hula hula dan tulang membawa "boras si pir ni tondi" (beras menguatkan roh hati" dan membawa "dengke" (ikan mas) kepada suhut (yang empunya acara/adat) sambil membawa ulos. Setelah acara hula hula dan tulang, barulah acara makan bersama dilaksanakan, dilanjutkan dengan mandok hata (memberi kata kata) dari hula hula, tulang, dongan sahuta (teman sekampung) baru kemudian acara ditutup dengan doa.

Dari serangkaian adat dalam acara memasuki rumah, ternyata setiap rangkaian acara memiliki fungsi dan makna ataupun 
tujuan acara tersebut. Acara memasuki rumah berkaitan erat dengan koteks dan konteks pertunjukan. Koteks meliputi unsur para linguistik, proksemik, kinetik, dan unsur material lainnya, sedangkan konteks meliputi dua hal yakni konteks situasi dan konteks budaya. Konteks situasi merupakan lingkungan atau tempat peristiwa berlangsung. Selain konteks situasi, konteks budaya pun turut mempengaruhi. Disamping memiliki fungsi dan makna, tradisi memasuki rumah merupakan warisan budaya yang memiiki nilai kearifan lokal. Acara memasuki rumah tidak hanya sebagai acara adat belaka yang dilakukan begitu saja, namun diluar daripada itu acara "mamongoti bagas" mengandung nilai kearifan lokal yang mencerminkan nilai-nilai budaya yang sangat penting untuk digali yang dapat dipergunakan atau dimanfaatkan untuk mengatur tatanan kehidupan masyarakat secara arif atau bijaksana.

Berdasarkan hal tersebut, penulis ingin membahas bagaimana teks, koteks dan konteks "mamongoti bagas" dan apa saja kearifan lokal yang terdapat pada tradisi "mamongoti bagas" pada masyarakat Batak Toba.

\section{PEMBAHASAN}

Deskripsi Tradisi Lisan "mamongoti bagas" (Memasuki Rumah Baru) dalam Masyarakat Batak Toba
Acara "mamongoti bagas" biasanya dilaksanakan didahului dengan acara kebaktian, yang dipimpin oleh bapak Pendeta. Pembukaan pintu rumah depan juga biasanya diserahkan kepada Bapak Pendeta dengan makna rumahnya akan diberkati Tuhan. Selesai acara kebaktian, acara adat kemudian dilaksanakan pada saat matahari mulai naik, sekitar pukul 10.00 pagi. Dilaksanakan pada saat matahri mulai naik memiliki makna agar kesejahtetaan dan kesehatan juga akan meningkat dalam keluarga di hari-hari mendatang.

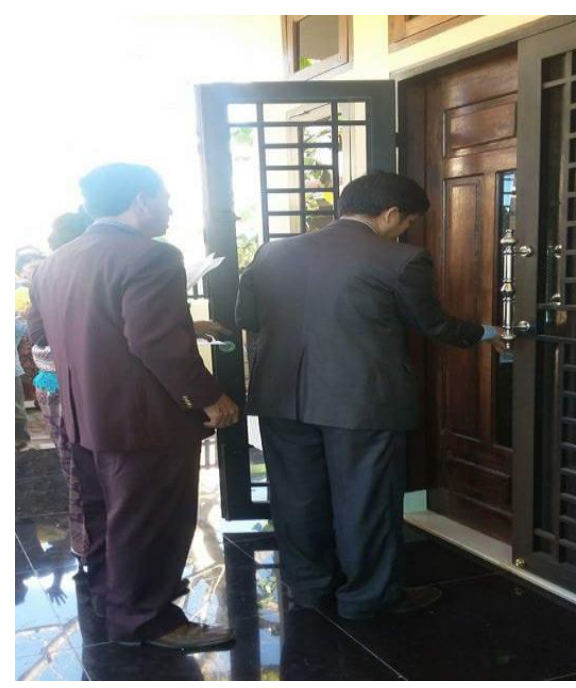

Gambar 2.1 Pendeta membuka pintu rumah sebelum memulai acara kebaktian

Ketika berbicara dalam acara adat, teman sekampung akan bertanya "sintuhu ni ulaon" (orang yang menjadi protokol dalam acara adat, biasanya sintuhu ni ulaon adalah teman semarga yang empunya adat. Misalnya yang empunya adat marga Silalahi, istri boru Pakpahan, maka yang sintuhu ni ulaon adalah marga Silalahi). 
Acara kemudian dilanjutkan dengan "manjalo tutur na ginokhon" ( apa jabatan dalam acara tersebut) sehigga tahu dimana posisi duduk. Dalam hal ini, sintuhu ni ulaon akan mengatakan demikian : Santabi ma di hamu na huparsangapi hami raja ni dongan sahuta, raja ni dongan tubu, raja ni boru, lumobi ma di raja i hulahula nami suang songon i dohot tulang nami, on ma tingki dohot ombas na naeng pungka on ta ma ulaon on, nuaeng pe dihamu hulahula nami suang songon i dohot tulang nami, bongot ma hamu raja nami nunga rade hami manjalo haroro ni rajai dohot angka nantulang nami.(Permisi kepada kalian yang kami hormati, raja teman sekampung, terlebih raja hula-hula kami dan juga tulang kami, inilah saatnya kita akan membuka acara kita, sekarang kepada hula hula dan juga tulang kami, masuklah kalian raja kami, kami sudah siap menyambut kedatangan raja dan juga nantulang kami)

Yang pertama di dalam rumah adalah pihak "suhut", jika pihak suhut sudah memaggil, barulah pihak hula-hula dan tulang masuk ke dalam rumah. Pihak teman sekampung dan boru juga duduk sesuai dengan tempat yang disediakan suhut. Kemudian paidua ni suhut (protokol) akan mengatakan kesiapan memulai acara adat dan menerima kedatangan hula-hula dan tulang. Ketika menerima kedatangan hula hula dan tulang, sebelum duduk, hula- hula dan tulang mengambil beras ke kepala suhut dan anak anaknya dan akan berkata “ horas jala pir ma tondim hela dohot ho inang borungku dohot angka pahompungku mangingani si baganding tuamon di dongani asi dohot holong nasian Amanta Debata" (sehat dan kuatlah roh kalian menantu dan putriku dan cucu-cucu ku menempati rumah masa tua ini, ditemani kasih dari Tuhan Allah) sambil dilemparkan keatas tiga kali dan dikatakan horas, horas, horas, Kemudian mereka duduk.

Acara berikutnya adalah "Pasahat tudutudu ni sipanganon dohot dengke" ( pemberian makanan dan ikan) oleh hulahula sambil memberi kata ketika memberi ikan. Biasanya akan dikatakan ucapan selamat dan semoga sehat selalu dalam menempati rumah baru, seperti halnya ikan, semoga keluarga juga saling berdampingan kemanapun pergi, sambil juga hula hula memberi ulos. Setelah hula-hula, Tulang juga akan berbuat hal yang sama, memberi ikan, kata dan ulos. 


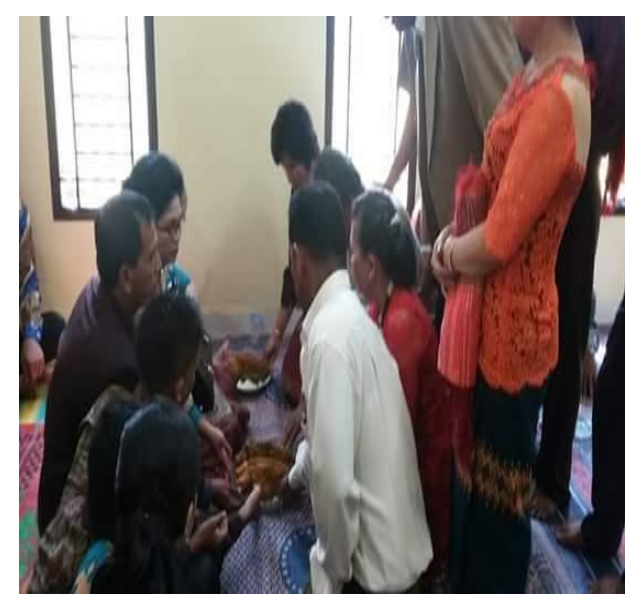

Gambar 2.2 Hula-hula dan Tulang memberikan ikan

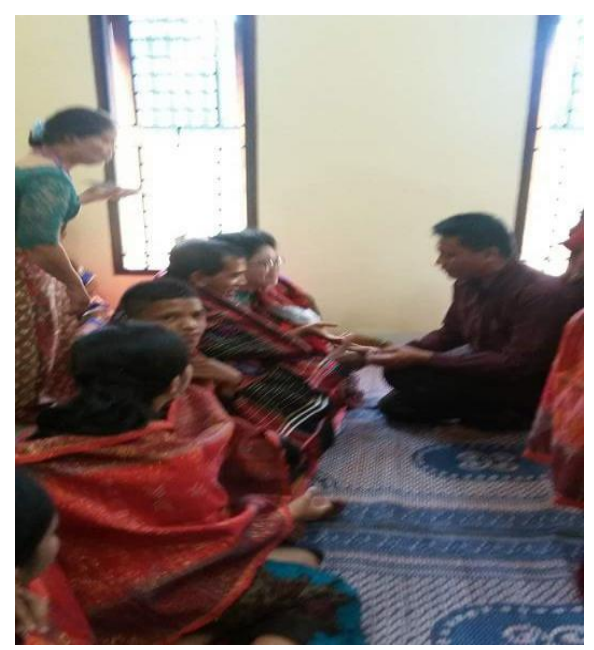

Gambar 2.3 Hula-hula memberikan ulos

Setelah hula-hula dan tulang selesai memberikan ikan dan ulos, acara selanjutnya adalah "marsipanganon" (acara makan). Setelah selesai acara "marsipanganon" dilanjutkan dengan acara "marbagi jambar" (membagi bagian dari daging). Dalam hal ini, bagian daging dibagiakan sesuai dengan posisi didalam acara adat, misal jika hula-hula mendapat bagian osang, tulang bagian gigi, dsb.

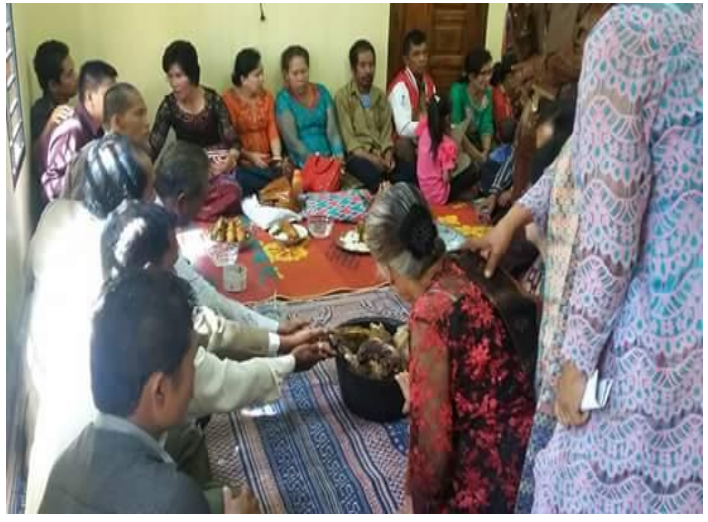

Gambar 2.4 Acara pembagian jambar

Setelah membagi jambar, kemudian akan dibuka acara "manghatai" (memberikan kata/ucapan selamat). Yang pertama meberikan kata adalah pihak boru, kemudian dongan tubu, dongan sahuta, dongan ale-ale (teman sepekerjaan), tulang dan baru kemudian hula hula. Kemudian "mangampu ma hasuhuton" (membalas kata kata yang sudah diucapkan semua pihak) yang pertama boru ni suhut baru kemudian pihak suhut. Sebelum suhut memberi ucapan terimakasih (pangampuon), pada acara akan diberikan piso piso dan tuak manis kepada pihak Hula-hula dan Tulang. Setelah pangompuan dari boru suhut dan suhut, barulah masuk acara terakhir "pangujungi ni ulaon" (akhir acara), dimana akan bernanyi dan berdoa. Doa akan dipimpin penatua gereja yang ada dalam acara, jika tidak ada, yang membuat doa adalah hulahula. Dalam acara memasuki rumah baru, ada beberapa hal yang harus dilakukan suhu seperti pantangan yang wajib dilakukan, seperti selama tiga hari setelah acara pesta 
tidak boleh membuang sampah diluar pagar dan tidak boleh mengeluarkan uang minimal 3 hari setelah acara pesta. Demikianlah deskripsi "mamongoti bagas" (memasuki rumah baru)

\section{Analisis Teks, Koteks dan Konteks}

Teks, koteks, dan konteks merupakan tiga bagian yang saling berhubungan sehingga pemahaman sebuah teks juga tergantung pada ko-teks dan konteksnya, dan juga sebaliknya. Di samping menganalisis hubungan proposisi dalam teks tradisi lisan, juga perlu menganalisis elemen koteks dan konteksnya untuk mendapatkan makna yang sebenarnya, makna paduan kalimat dalam wacana tradisi lisan baru dapat dipahami secara lengkap setelah dikaitkan dengan ko-teks dan konteksnya. Teks memiliki struktur, ko-teks memiliki elemen, dan konteks memiliki kondisi, yang formulanya dapat diungkapkan dari kajian tradisi lisan.

\section{Analisis Teks}

Dalam penelitian tradisi lisan "mamongoti bagas" masyarakat Batak Toba, analisis teks dilakukan dengan cara menemukan tema maupun topik yang merupakan makna secara keseluruhan dari rangkaian acara "mamongoti bagas" tersebut, mengungkapkan pesan-pesan apa yang ada dalam setiap elemen teks.
Acara "mamongoti bagas" memiliki makna mengucap syukur kepada Tuhan karena sudah diberikan rejeki sehingga bisa membangun rumah sebagai tempat bersama, tempat menua berkumpul bersama keluarga. Rumah adalah hal yang sangat penting bagi masyarakat Batak, maka tidak jarang orang tua selalu menasehatkan anaknya walaupun sudah menikah untuk menabung uang agar nantinya bisa membangun rumah. Dari hal ini, acara "mamongoti bagas" merupakan ucapan rasa syukur kepada Tuhan, sehingga ditandai dengan permulaan acara adalah kebatian yang dipimpin Pendeta. Selain rasa syukur acara "mamongoti bagas" juga media untuk meminta doa kepada keluarga besar, teman, dan teman sekampung terkhusus hula-hula dan tulang, agar tetap sehat dan diberkati ketika nantinya tinggal di rumah yang baru.

Selain rasa ucapan syukur, pada dasarnya semua rangkaian acara "mamongoti bagas" merupakan sebagai pertanda masuk huta ( memasuki kampung baru ). Acara memasuki rumah baru memiliki makna sebagai penanda kepada masyarakat di kampung itu bahwa ada keluarga baru di kampung tersebut. Ini juga memiliki makna, bahwa keluarga baru yang ada di kampung tersebut nantinya akan wajib mengikuti aturan norma masyarakat yang berlaku di daerah tersebut. 


\section{Analisis Koteks}

Ko-teks menurut Sibarani (2012: 242) adalah keseluruhan unsur yang mendampingi teks seperti unsur paralinguistik, proksemik, kinetik, dan unsur material lainnya. Deskripsi paralinguistik mencakup intonasi, aksen, jeda, dan tekanan. Peranan kajian paralinguistik sangat penting ketika tradisi dinyayikan atau disenandungkan sebagaimana karakteristik kebanyakan tradisi lisan. Kinetik merupakan bidang ilmu yang mengkaji gerak isyarat. Dalam tradisi lisan, gerak isyarat sangat berperan karena karakteristik tradisi lisan yang berupa kegiatan, peristiwa atau pertunjukan. Dalam melakonkan tradisi lisan, gerak isyarat itu lebih luas perannya karena meliputi berbagai tarian atau gerakan lain yang tidak sekedar sebagai pendamping dan pengganti teks verbal dalam komunikasi.

Proksemik merupakan bidang ilmu yang mempelajari penjagaan jarak antara pembicara dan pendengar sebelum dan ketika sedang terjadi komunikasi. Deskripsi sikap dan penjagaan jarak antar pelaku dan antara pelaku dengan penonton akan memberikan kontribusi pada interpretasi makna dalam tradisi lisan. Dari penjagaan jarak para pelaku dapat terlihat oposisi binari antar pelaku, yang menggambarkan peran sebagai raja-rakyat, majikan- pembantu, direktur-karyawan, pimpinanbawahan, orang kaya-orang miskin, dan sebagainya. Bentuk ko-teks lain yang sangat perlu dikaji dalam tradisi lisan adalah unsur material atau benda yang sering mendampingi penggunaan teks. Unsur-unsur material yang dipergunakan dalam praktik tradisi lisan dapat berupa perangkat pakaian dengan gayanya, penggunaan warna dengan ragam pilihannya, penataan lokasi dengan dekorasinya, dan penggunaan berbagai properti dengan fungsi masing-masing. Dengan demikian, kajian semiotik terhadap unsur-unsur material yang simbolik sebagai bagian dari ko-teks perlu dilakukan dalam memahami tradisi lisan.

Dalam penelitian "mamongoti bagas" dalam masyarakat Batak Toba terdapat unsur proksemik, dimana ada penjagaan jarak antara pembicara dan pendengar sebelum dan ketika sedang terjadi komunikasi. Dalam hal "mamongoti bagas" jelas terlihat penjagaan jarak para pelaku yang menggambarkan peran sebagai hula-hula, tulang, dongan tubu, pidua ni suhut, pariban, teman dan masyarakat di kampung.

Dalam acara "mamongoti bagas" jelas terlihat bahwa yang memberi ikan dan ulos adalah hula-hula dan tulang. Ini jelas memiliki makna bahwa, hula-hula dan 
tulang sangat memiliki peran penting dalam acara "mamongoti bagas". Orang akan mengetahui apa posisi seseorang dalam acara "mamongoti bagas" sehingga mereka akan tau apa yang dibawanya. Jika dia Hula-hula atau Tulang tentu akan membawa ikan mas dan ulos sebagai simbol memberi berkat. Ikan Mas dan ulos menajadi pendamping material yang memiliki makna agar sehat sehat (hipashipas) dalam memasuki rumah baru. Sama halnya ketika acara adat mau dimulai, hulahula dan tulang memiliki kedudukan yang sangat dihormati, mereka masuk rumah, baru acara dimulai dan hula hula dan tulang mengambil beras dan melemparkannya keatas tiga kali sambil mengucapkan horas tiga kali, yang juga memiliki makna semoga sehat-sehat dan diberkati lah seisi rumah. Jika perannya sebagai dongan tubu dan pariban, tentu tidak membawa ulos, namun membawa tumpak (uang di amplop), jika perannya dongan sahuta (teman sekampung), maka akan membawa tandok (beras).

Dari penjelasan tersebut sudah sangat jelas bahwa unsur proksemik dan material membagun acara tradisi "mamongoti bagas".

\section{Analisis Konteks}

Sistem konteks sosial berada pada tingkat semiotik konotatif bahasa yang terdiri dari konteks situasi, konteks budaya dan ideologi (Sinar, 2010: 54). Dalam pemahaman tradisi lisan ketiga istilah tersebut terangkum dalam konteks sosial dan konteks situasi. Konteks sosial ini meliputi orang-orang yang terlibat seperti pelaku, pengelola, penikmat dan bahkan komunitas pendukungnya. Konteks situasi mengacu pada waktu, tempat dan cara penggunaan teks. Konteks penuturan dalam penelitian ini pada hakikatnya mengenai latar atau tempat berlangsungnya acara "mamongoti bagas", waktu berlangsungnya "mamongoti bagas", siapa yang terlibat dalam acara "mamongoti bagas", dan suasananya.

1. Konteks Situasi

- Acara "mamongoti bagas" berlangsung di dalam rumah yang baru. Tepatnya di ruang tengah. Ruang tengah menjadi tempat melangsungkan tata acara tradisi "mamongoti bagas" karena ruang tamu lah bagian yang paling luas dalam suatu rumah. Ruang tamu juga sebagai tempat menerima tamu, yang berarti ketika mengadakan acara "mamongoti bagas", bahwa pihak yang empunya rumah, siap menyambut siapapun yang datang berkunjung ke rumah mereka.

- Waktu berlangsungnya acara "mamongoti bagas". Acara "mamongoti bagas" dimulai di pagi hari sekitar pukul 10.00 pagi, naiknya matahari keatas (partuat ni mataniari) yang memiliki makna agar berkat dan kesejahteraan juga akan meningkat ketika nantinya menempati rumah yang baru. Acara 
demi acara akan berlangsung, dan biasanya akan selesai di siang hari, setelah makan bersama dan memberi kata dari hula-hula, tulang, dongan sahuta, dan kemudian dibalas oleh istri suhut dan suhut (yang empunya pesta).

- Suasana ketika berlangsungnya acara "mamongoti bagas" adalah ramai karena banyak tamu dan keluarga besar yang hadir.

2. Konteks Sosial acara "mamongoti bagas"

Konteks sosial mengacu pada faktor-faktor sosial yang mempengaruhi atau menggunakan konteks. Konteks sosial ini meliputi orang-orang yang terlibat seperti pelaku, pengelola, penikmat dan bahkan komunitas pendukungnya. Dalam acara "mamongoti bagas" yang menjadi pelaku adalah pihak suhut (yang empunya pesta), dalam hal ini, yang membantu suhut mempersiapkan acara pesta adalah boru, pihak yang semarga dengan suhut. Dalam acara "mamongoti bagas", hula-hula dan tulang tentu memiliki peranan penting, sebagai yang dihormati dan pemberi berkat. Orang lain yang terlibat adalah dongan sahuta (teman sekampung) karena itu adalah salah satu tujuan acara "mamongoti bagas" untuk memperkenalkan diri kepada warga di daerah yang baru tersebut.

\section{Kearifan Lokal Ritus Batak Toba "mamongoti bagas"}

Kearifan lokal merupakan gagasangagasan atau nilai-nilai, pandanganpandangan setempat atau lokal yang bersifat bijaksana, penuh kearifan, bernilai baik yang tertanam dan diikuti oleh anggota masyarakatnya. Kearifan lokal merupakan perpaduan antara nilai-nilai suci firman Tuhan dan berbagai nilai yang ada. Kearifan lokal terbentuk sebagai keunggulan buadaya masyarakat setempat maupun kondisi geografis dalam arti luas. Kearifan lokal merupakan produk budaya masa lalu yang patut secara terus menerus dijadikan pegangan hidup. Meskipun bernilai lokal tetapi nilai yang terkandung di dalamnya dianggap sangat universal.

Kearifan lokal memiliki suatu nilai tersendiri yang mana nilai-nilai yang terkandung dalam kearifan lokal dapat tercermin dalam kehidupan sehari-hari. Adapun kearifan lokal yang mencerminkan nilai budaya diantaranya adalah kesejahteraan, kerja keras, disiplin, pendidikan, kesehatan, gotong royong, pengelolaan jender, pelestarian dan kreativitas budaya, peduli lingkungan, kedamaian, kesopansantunan, kejujuran, kesetiakawanan sosial, kerukunan dan penyelesaian konflik, komitmen, pikiran positif, dan rasa syukur (Sibarani, 2012:133-134) yang dikelompokkan menjadi kearifan lokal inti (core local wisdom) yaitu kesejahteraan dan kedamaian. Dalam penelitian ini, penulis menemukan ada 3 kearifan lokal yang dapat ditemukan dalam ritus "mamongoti bagas" dalam masyarakat Batak Toba, yaitu : 


\section{Ucapan Syukur}

Acara "mamongoti bagas" mengandung kearifan lokal ucapan syukur. Acara "mamongoti bagas" menjadi acara untuk mengucap syukur atas kebaikan Sang Pencipta yang sudah memberikan rejeki sehingga bisa membangun sebuah rumah sebagai tempat bernaung dan berkumpul bersama keluarga. Ucapan Syukur ini ditandai dengan acara kebaktian yang dilakukan sebelum memasuki acara adat memasuki rumah baru. Ini adalah salah satu bukti bahwa berterimakasih kepada Sang Pencipta yang sudah memberikan rejeki adalah hal yang utama.

Membuat acara "mamongoti bagas" dengan memberi makan warga sekampung juga merupakan bentuk ucapan syukur yang dilakukan yang empunya pesta. Bersyukur masih diberi kesehatan dan rejeki, dan sekaligus meminta doa kepada semua yang hadir agar tetap senantiasa dalam lindungan Tuhan.

\section{Kerukunan dan Kedamaian}

Acara "mamongoti bagas" mengandung nilai kearifan lokal kerukunan dan kedamaian. Acara memasuki rumah baru menggambarkan sebuah kebersamaan, dimana masuknya satu anggota baru dalam sebuah kampung. Ini menjadi penanda untuk memperkuat persaudaraan, dimana keluarga memperkenalkan diri secara resmi kepada warga kampung bahwa ada mereka warga baru di daerah tersebut dan akan siap mengikuti aturan yang berlaku di daerah tersebut. Ini menandakan ada kerukunan dan kedamaian yang terjalin antara pihak suhut (yang empunya pesta) sebagai warga baru di kampung dengan semua warga sekitar. Hal ini menandakan kerukunan dan kedamaian, bahwa dari awal, keluarga sudah memperkenalkan diri kepada masyarakat dan semoga dikemudian hari hubungan dengan sesama juga rukun dan damai.

\section{Peduli Lingkungan}

Dalam acara "mamongoti bagas" ada kearifan lokal yang terkandung didalamnya yaitu peduli lingkungan. Acara "mamongoti bagas", terutama yang penulis amati di daerah Pakkat, Humbang Hasundutan, memiliki pantangan bahwa selama tiga hari berturut turut setelah acara pesta "mamongoti bagas", maka yang empunya rumah dilarang membuang sampah keluar dari halaman rumah. Ini maksudnya adalah, agar yang empunya rumah peduli lingkungan di daerah yang baru mereka tempati, bahwa tidak boleh membuang sampah sembarangan.

\section{PENUTUP}

Teks dalam acara "mamongoti bagas" dalam masyarakat Batak Toba memiliki makna secara keseluruhan pembentukan hubungan sosial yang baru, bahwa ada warga baru di kampung tersebut yang akan siap menerima aturan dan norma yang berlaku di daerah tersebut. Koteks 
dalam acara "mamongoti bagas" mengandung unsur proksemik, dimana ada jeda diantara penutur, sehingga kita tahu apa posisi seseorang di dalam acara "mamongoti bagas". Konteks dalam acara "mamongoti bagas" terdiri dari konteks situasi dan sosial. Konteks situasi dimana acara dimulai di pagi hari sekitar pukul 10.00 ketika matahari mulai menanjang naik, sehingga harapannya adalah rejeki dan berkat bagi yang empunya acara juga akan meningkat, dan biasanya akan berkahir di siang hari. Tempat acara adalah di dalam rumah yang baru, tepatnya di ruang tengah. Dalam konteks sosial pelaku yang terlibat adalah keluarga besar (hulahula, tulang, dongan tubu, pariban), teman, dan warga sekampung. Acara "mamongoti bagas" mengandung tiga kearifan lokal, yaitu ucapan syukur, kerukunan dan kedamaian, dan peduli lingkungan.

\section{DAFTAR PUSTAKA}

Barthes, Roland. (2007). Petualangan Semiologi. Yogyakarta: Pustaka Pelajar.

Barthes, Roland. (2009). Mitologi. Yogjakarta: Kreasi Wacana.
Cook, Guy. (1994). Discourse. Oxford: Oxford University Press.

Halliday, M.A.K. (1978). Language as Social Semiotics. London: University Park Press.

Halliday, M.A.K. Hasan R. (1985). Language, Context, and Text: Aspect of Language in A Social Semaiotic Perspective. London: Oxford University Press.

Hasugian, Monika. (2017). Upacara Kematian Saur Matua Batak Toba : Analisis Tradisi Lisan. Jurnal Lingua Vol.14. No.2.

Koentjaraningrat. (1997). Pengantar Ilmu Antropologi. Jakarta: Rineka Cipta

Pudentia. (2007). Metodologi Kajian Tradisi Lisan. Jakarta: Asosiasi Tradisi Lisan.

Sibarani, Robert. (2012). Kearifan Lokal : Hakikat, Peran, dan Metode Tradisi Lisan. Jakarta: Asosiasi Tradisi Lisan.

Silaban, D.M.P. (2015). Tradisi Lisan Nyanyian Rakyat Anak-Anak Pada Masyarakat Batak Toba di Kecamatan Lintongnihuta Kabupaten Humbang Hasundutan. Tesis pada Program Pasca Sarjana USU.

Sinar, T.S, M.Takari. (2014). Teori dan Metode untuk Kajian Tradisi Lisan. Medan : Mitra 